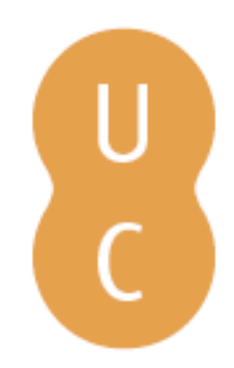

\title{
pommalina
}

\section{As bibliotecas universitárias: seu papel de mediação para o acesso ao conhecimento na era digital}

\author{
Autor(es): $\quad$ Ribeiro, Fernanda \\ Publicado por: Imprensa da Universidade de Coimbra \\ URL \\ persistente: URI:http://hdl.handle.net/10316.2/36979 \\ DOI: $\quad$ DOI:http://dx.doi.org/10.14195/978-989-26-1045-0_8 \\ Accessed : $\quad$ 26-Apr-2023 13:52:11
}

A navegação consulta e descarregamento dos títulos inseridos nas Bibliotecas Digitais UC Digitalis, UC Pombalina e UC Impactum, pressupõem a aceitação plena e sem reservas dos Termos e Condições de Uso destas Bibliotecas Digitais, disponíveis em https://digitalis.uc.pt/pt-pt/termos.

Conforme exposto nos referidos Termos e Condições de Uso, o descarregamento de títulos de acesso restrito requer uma licença válida de autorização devendo o utilizador aceder ao(s) documento(s) a partir de um endereço de IP da instituição detentora da supramencionada licença.

Ao utilizador é apenas permitido o descarregamento para uso pessoal, pelo que o emprego do(s) título(s) descarregado(s) para outro fim, designadamente comercial, carece de autorização do respetivo autor ou editor da obra.

Na medida em que todas as obras da UC Digitalis se encontram protegidas pelo Código do Direito de Autor e Direitos Conexos e demais legislação aplicável, toda a cópia, parcial ou total, deste documento, nos casos em que é legalmente admitida, deverá conter ou fazer-se acompanhar por este aviso.

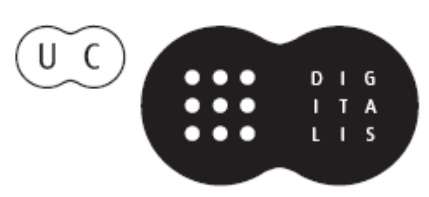



Tendo como pano de fundo as Comemorações dos seus 500 anos, a Biblioteca Geral da Universidade de Coimbra organizou um Congresso Internacional subordinado ao tema "A Biblioteca da Universidade: permanência e metamorfoses", que teve lugar nos dias 16, 17 e 18 de janeiro de 2014, no auditório da Reitoria da Universidade de Coimbra.

O objetivo maior desta reunião científica foi o de refletir sobre o presente e o futuro das bibliotecas que servem públicos universitários. Numa outra vertente, procurou chamar-se a atenção para a importância de que a Biblioteca se reveste, tendo em vista o progresso do conhecimento técnico e científico. Por último, o Congresso pretendeu instituir-se como oportunidade de reflexão prospetiva e como lugar de encontro entre as sensibilidades de todos os que trabalham profissionalmente com livros e com outros suportes de natureza bibliográfica.

Nesse sentido, foram apresentadas Conferências, Mesas Redondas e sessões de Testemunhos em torno de temas como o valor das bibliotecas universitárias, a biblioteca universitária em contexto; as mudanças e os desafios; a biblioteca universitária e a sociedade da informação e conhecimento; o impacto do acesso aberto na comunidade científica, e as bibliotecas digitais. 
FERNANDA RIBEIRO

Universidade do Porto

University of Porto

\author{
AS BIBLIOTECAS UNIVERSITÁRIAS: \\ SEU PAPEL DE MEDIAÇÃO PARA O ACESSO \\ AO CONHECIMENTO NA ERA DIGITAL \\ UNIVERSITY LIBRARIES: THEIR ROLE AS MEDIATORS \\ IN ACCESS TO KNOWLEDge IN THE DIgital AgE
}

\begin{abstract}
RESUMO: Numa comunicação que pretende, sobretudo, apresentar-se como um conjunto de reflexões sobre o papel das bibliotecas das universidades, começa-se por traçar uma panorâmica geral e diacrónica da evolução destas bibliotecas enquanto serviços de informação com um cunho marcadamente orgânico, cujos objetivos sempre se enquadraram na missão das instituições de que faziam parte.

$\mathrm{Na}$ sociedade digital e em rede, esta caraterística permanece como fator identitário das bibliotecas universitárias, pese embora o facto de terem de enfrentar novos desafios para os quais se exigem competências também de novo tipo. O seu perfil custodial e tecnicista, que lhes conferia um estatuto de repositórios/tesouros do saber, está em profunda alteração, a qual as reconfigura como repositórios dinâmicos, que não têm por objetivo essencial a custódia, mas sim a mediação e a partilha em rede, à escala global, da informação (conhecimento) gerada, acumulada e utilizada pelas universidades no desempenho da sua atividade pedagógica, científica e de transferência de conhecimento para a sociedade.
\end{abstract}

ABSTRACT: In a paper that aims, above all, to be a set of reflections on the role of university libraries, we begin by drawing a general and diachronic overview of the evolution of these libraries while information services with a distinctive organic profile, whose goals always fit in the mission of the institutions to which they belonged.

In the digital and networked society, this feature remains as an identity factor of university libraries, despite the fact that they have to face new challenges for which new skills are required. Their custodial and technicist profile, which gave them the status of repositories/treasures of knowledge, is in deep change what reshapes them as dynamic repositories that do not have custody as essential goal, but mediation and network sharing, at global scale, of the information (knowledge) generated, accumulated and used by universities in the performance of their scientific educational and knowledge transfer to society activities. 


\section{Traços da evolução das bibliotecas universitárias}

\subsection{Das origens à Modernidade: as bibliotecas ao serviço das instituições}

Embora houvesse, no início da Idade Média, algumas escolas que poderiam ser consideradas instituições de ensino superior, só no final do século XII é que a universidade surgiu como tal. Porém, nos primórdios da sua instituição, mais do que organizações estabelecidas, existiam grupos de estudantes que se reuniam em torno de professores para aprender o que eles tinham para ensinar. Esta forma de ensino levava mesmo alguns estudantes a circular entre cidades e países à procura dos melhores mestres e os grupos que se formavam constituíram os núcleos das primeiras universidades que, significativamente, davam pelo nome de studium generale.

A instituição das universidades, na Europa, ao longo do século XIII, sofreu a influência da Constantinopla medieval, que serviu de inspiração, sobretudo, às universidades estabelecidas em território de domínio muçulmano, na Península Ibérica. Estudantes que haviam estudado no Oriente traziam consigo livros em latim, que eram traduções das versões árabes dos gregos clássicos, assim como obras de cientistas muçulmanos, que dessa forma eram difundidas no Ocidente.

Em cidades de Itália (Salerno, Bolonha), de França (Paris, Montpellier), de Inglaterra (Oxford, Cambridge), dos reinos que viriam a constituir a futura Espanha (Salamanca, Toledo, Sevilha), de Portugal (Lisboa, Coimbra) e noutros locais da Europa, estabeleceram-se, ao longo das centúrias de duzentos e trezentos, as primeiras universidades, muitas delas resultantes da evolução de escolas e colégios religiosos, que funcionavam junto a catedrais ou mosteiros.

Durante muito tempo as universidades não tinham bibliotecas e era comum serem os professores a emprestar os próprios livros aos estudantes mais aplicados, que os copiavam e, por vezes, até vendiam as cópias efetuadas a livreiros que se instalavam junto das universidades.

Em Oxford e Cambridge os grupos de estudantes evoluíram para os "colleges" (semelhantes às modernas faculdades), os quais começaram a 
estabelecer as suas próprias bibliotecas, mas na generalidade dos países da Europa as bibliotecas gerais/centrais das universidades raramente surgiram antes do século XIV.

As bibliotecas das universidades de Paris e de Oxford serviram de modelo para a maior parte das bibliotecas universitárias ${ }^{1}$. Eram espaços de dimensão reduzida (só após a invenção da tipografia é que os acervos começam a aumentar), com poucos lugares para trabalho sentado e os livros mais valiosos encontravam-se presos com cadeias em ferro. A leitura e o estudo realizavam-se na mesma sala onde se armazenavam os livros (em estantes) e estes estavam organizados segundo uma classificação que, geralmente, se dividia nas matérias do trivium e do quadrivium, teologia, medicina e jurisprudência.

A partir da literatura que se conhece sobre as bibliotecas universitárias medievais e modernas, o que se pode afirmar sem qualquer dúvida é que elas se estabeleceram, desde as origens, com um forte vínculo orgânico às instituições de que dependiam - as universidades - e funcionavam como setores/serviços bem enquadrados no contexto dessas mesmas instituições.

Que tipo de serviço(s) prestavam as bibliotecas universitárias? Quem eram os seus utilizadores? Que funções primordiais desempenhavam? Qual o seu papel como mediadoras no acesso à informação/conhecimento?

A resposta a estas questões pode ser dada de forma sucinta, recorrendo a autores que desde há largos anos se dedicam ao estudo e investigação sobre a história das bibliotecas, contemplando nas suas obras o caso particular das bibliotecas das universidades.

Michael Harris ou Fred Lerner são dois autores que têm investigado a história das bibliotecas e, a partir dos seus escritos, podemos sistematizar em poucas linhas aquilo que eram os traços identitários mais importantes das bibliotecas universitárias medievais ${ }^{2}$.

1 O que se conhece sobre as bibliotecas das universidades de Paris e de Oxford permite ter uma ideia aproximada da forma como funcionavam as primitivas bibliotecas universitárias. Sobre o assunto, ver: HARRIS, Michael H. - History of libraries in the Western world. 4th ed. Lanham; London: The Scarecrow Press, 1995. ISBN 0-8108-2972-X.

2 Ver: HARRIS, Michael H. - History of libraries in the Western world; LERNER, Fred - The Story of libraries from the invention of writing to the computer age. New York: Continuum, 1998. ISBN 0-8264-1114-2. 
Até à Idade Moderna, as bibliotecas universitárias eram as herdeiras diretas das bibliotecas dos mosteiros ou das catedrais, mas diferiam delas, sobretudo, porque eram locais de trabalho e de estudo. Eram constituídas, essencialmente, por doações de bibliotecas privadas de professores e possuíam acervos relativamente pequenos, apesar de a criação das universidades ter estimulado o desenvolvimento de oficinas laicas de copistas, produtores de livros, que iam enriquecendo os fundos das bibliotecas universitárias.

Da organização interna destas bibliotecas sabemos pouco, mas há notícias de que as obras se dispersavam por núcleos, que podiam corresponder a áreas de estudo, e dessa forma se organizava um sistema de arrumação que podemos considerar como uma classificação ainda elementar, mas que evidenciava, naturalmente, alguma lógica na estruturação dos agrupamentos. As obras, materializadas em códices encadernados em couro, eram consideradas valiosas (por serem raras e em escasso número) e, por isso, estavam presas com correntes para não poderem ser retiradas dos seus lugares ${ }^{3}$. Porém, apesar deste cuidado com a salvaguarda das espécies, conhecem-se casos de bibliotecas que praticavam o empréstimo para fora das suas instalações e os leitores podiam levar para casa obras de menor porte.

Do ponto de vista técnico, o trabalho era também muito pouco apurado. Aliás, o exercício de atividades bibliográficas propriamente ditas só se pode considerar verdadeiramente em desenvolvimento após a invenção da tipografia. Os catálogos ou registos de controlo das espécies eram muito incipientes e não havia ainda bibliotecários como profissionais especializados. A guarda das obras estava, muitas vezes, a cargo de um funcionário da universidade ou mesmo de um estudante.

As bibliotecas eram locais para serviço exclusivo de professores e alunos, o que mostra bem o seu forte vínculo orgânico às instituições em que se integravam e das quais dependiam. Este traço identitário conti-

3 O exemplo mais antigo, em Inglaterra, destes livros "encadeados" data de 1320, na biblioteca de Oxford; igualmente há notícias deste tipo de livros na Sorbonne, pela mesma época, havendo mesmo um inventário com o registo de 330 volumes encadeados (ver MASSON, André; SALVAN, Paule - Les Bibliothèques. 4.ème éd. mise à jour. Paris: PUF, 1975, p. 14). 
nua, ainda hoje, a marcar a diferença entre as bibliotecas universitárias e outras bibliotecas em que o enquadramento institucional/organizacional não tem um peso tão significativo (por exemplo, as bibliotecas públicas).

O período medieval das bibliotecas universitárias foi a fase da sua constituição e consolidação. Não se pode ainda falar em desenvolvimento pleno, mas a sua proliferação em vários países começa a ser considerável. Segundo Michael Harris, antes de 1500, em toda a Europa, havia mais de 75 bibliotecas universitárias, "desde Sevilha, na Espanha, até Upsala, na Suécia, e desde Catania, na Sicília, até Aberdeen, na Escócia”

A partir de meados do século XV, e após a invenção da técnica de imprimir com carateres móveis por Johannes Gutenberg, as bibliotecas em geral e as universitárias em particular sofreram uma evolução muito significativa, que se traduziu, desde logo, no aumento considerável da quantidade de livros que passaram a ter disponíveis para os seus utilizadores. O incremento do comércio livreiro e a produção mecânica das obras levaram rapidamente a um crescimento, em dimensão e em número, das bibliotecas das universidades e ao desenvolvimento da técnica bibliográfica. O período que medeia entre os séculos XV e XIX ficou conhecido pelo epíteto de "período humanista" e teve como característica dominante a produção de repertórios bibliográficos especializados, ou seja, dedicados a áreas particulares do conhecimento (religião, medicina, jurisprudência, filosofia, etc.), cujas obras mais representativas se encontravam nos fundos das bibliotecas universitárias. Na verdade, pode-se considerar que a invenção da imprensa esteve na base da moderna Biblioteconomia, na medida em que o enorme aumento do número de livros e dos acervos das bibliotecas fez surgir uma profissão com a responsabilidade de organizar e gerir os fundos bibliográficos, emergindo também uma técnica de representação descritiva que haveria de dar origem, nos finais do século XVIII, aos primeiros trabalhos de catalogação, no sentido moderno do termo.

4 Tradução da autora, a partir de HARRIS, Michael H. - History of libraries in the Western world, p. 112. 


\subsection{O pós-liberalismo: uma mediação custodial e tecnicista}

A afirmação disciplinar da Biblioteconomia e da Arquivística e o consequente reforço da sua vertente mais tecnicista são consequências inegáveis da Revolução Francesa, dos ideais do Liberalismo e de todo o processo de nacionalizações que foi desencadeado, transferindo para a posse do Estado a documentação imprescindível à gestão patrimonial dos bens usurpados às classes dominantes no Antigo Regime e à redação da História da Nação, ideal muito caro aos revolucionários que impuseram a nova ordem liberal.

Com a concentração de tão grande quantidade de documentação nas mãos do Estado vão surgir problemas novos, como, por exemplo, a necessidade de espaços para instalar convenientemente os documentos e a exigência de profissionais qualificados para organizar, catalogar e difundir os acervos reunidos. A criação de instituições/serviços destinados a conservar e a gerir as massas documentais nacionalizadas seguiu, em toda a Europa, o modelo institucionalizado em França com a Bibliothèque Nationale de Paris (fundada a partir da biblioteca real e enriquecida com os fundos usurpados às ordens religiosas) e os Archives Nationales (criados para concentrar os títulos relativos aos bens patrimoniais das classes do Antigo Regime que haviam sido afastadas do poder).

As incorporações feitas em bibliotecas implicaram também a criação de espaços para depósitos, uma vez que as estantes das salas de leitura eram manifestamente insuficientes para instalar a documentação incorporada, e obrigaram a uma formação profissional mais adequada ao desenvolvimento da vertente tecnicista, que tinha em vista o tratamento e a disponibilização da informação a todos os cidadãos, cumprindo-se, assim, as determinações legislativas revolucionárias sobre o acesso à informação.

A prática profissional de bibliotecários e arquivistas, associada à criação, no pós-Revolução Francesa, de serviços de informação com um carácter institucional e público, englobou, desde logo, uma variável que foi evoluindo até hoje, a ponto de se tornar crucial na Era da Informação em que vivemos - disponibilizar a informação a quem dela precisa. Este aspeto constituiu, desde sempre, o âmago das bibliotecas universitárias, 
uma vez que nestas bibliotecas o uso da informação é muito mais uma questão de trabalho do que um deleite intelectual ou uma mera fruição ou lazer.

A atividade dos profissionais das bibliotecas incluiu, e continua a incluir, como componente essencial a função de mediadoras de informação. Os serviços de informação situam-se entre a informação e os utilizadores que dela precisam (a usam, a consomem...) e os profissionais/bibliotecários funcionam como intermediários, como mediadores.

Este papel de mediação deu, durante muito tempo, ao profissional da informação um estatuto de técnico especializado e erudito, que o transformava num elemento indispensável no processo de localização e recuperação da informação. No século XIX, a liberalização do acesso à informação e a transformação do perfil das bibliotecas em serviços públicos, pagos pelo Estado com o dinheiro dos cidadãos, enfatizou este papel mediador dos bibliotecários e deu-lhes um estatuto e um poder de grande relevância, dada a sua especialização e domínio de ferramentas técnicas pouco familiares aos que precisavam de aceder à informação. Mas, por outro lado, a este papel de crucial importância acabava por, perversamente, se aliar um poder muito peculiar, um domínio sobre a informação, que fazia do bibliotecário um elemento-chave em todo o processo.

A elaboração de instrumentos de pesquisa, a decisão sobre os elementos descritivos a usar na representação dos documentos e, especialmente, na criação de pontos de acesso aos conteúdos, foi, desde sempre, um aspeto da profissão do bibliotecário que o fez, de certa forma, "dominar" e deter a tutela sobre a informação que tinha à sua guarda e que disponibilizava consoante critérios, de forma alguma neutros e objetivos.

Na tradição custodial, historicista e patrimonialista, a ideia da preservação e da guarda da memória sempre teve uma prevalência muito grande sobre a ideia do acesso e, nessa ótica, geravam-se muitas vezes situações perversas, constrangedoras do pleno uso da informação, consagrado na legislação saída da Revolução Francesa.

Só a título de exemplo, vejamos o que António Ferrão - um bibliotecário esclarecido, competente e moderno, muito avançado para o seu tempo e 
em clara sintonia com os desenvolvimentos da área a nível internacional - escreveu sobre Xavier da Cunha, que exercera o cargo de diretor da Biblioteca Nacional em 1905. O pequeno excerto, do punho de António Ferrão, que a seguir se transcreve, ilustra bem a visão "anti-acesso", provocada pelo excesso de zelo sobre a custódia dos fundos documentais, que caracterizava este tipo de bibliotecários:

Para que se veja como esse director estava fora do seu tempo e, pouco estudara dos assuntos de biblioteconomia, basta que se diga que ele, ainda nesse ano de 1905, manifestava-se contra a abertura da leitura nocturna, que o Governo, benemeritamente, estabeleceu por esse tempo, e, até mesmo, contra a diurna, em Agosto e Setembro, servindo-lhe de argumento que o Arquivo da Torre do Tombo não fornecia tal leitura nocturna, como se fosse bom senso comparar regimes de estabelecimentos tão díspares. (...) O pior para nós - então leitores assíduos da Biblioteca Nacional - é que Xavier da Cunha considerava "ociosos» os frequentadores diários do estabelecimento que dirigia, defendendo - ele e outros bibliotecários do tempo e posteriores - o peregrino critério que a Biblioteca Nacional existia principal, se não exclusivamente, para benefício e utilização dos seus funcionários ${ }^{5}$.

Esta perspetiva custodial não era apanágio da Biblioteca Nacional e das bibliotecas públicas, mas sim da generalidade dos serviços de informação que se instituíram no pós-Revolução Francesa, seguindo o modelo originado em França e que assentava na ideia liberal de conservação/ concentração nas mãos do Estado dos acervos documentais considerados imprescindíveis para legitimar a história da Nação. Neste quadro, as bibliotecas universitárias conservaram alguns traços identitários, algo distintos, fruto do seu arreigado vínculo orgânico e do fortalecimento do seu papel no apoio ao desenvolvimento humanístico e científico protagonizado pelas universidades, pese embora o facto de também exercerem o mesmo tipo de mediação custodial e passiva de que estamos a falar.

5 FERrão, António - Gabriel Pereira: a sua educação e cultura, a sua época e a sua obra. Anais das Bibliotecas e Arquivos. Lisboa. 2. ${ }^{a}$ série. 19 (1947) p. 82-83. 
A ilustrar tal facto, veja-se o célebre livrinho de Umberto Eco, intitulado A Biblioteca $^{6}$, no qual o autor faz uma caricatura mordaz da perversão exercida na prática mediadora dos bibliotecários, aliás na linha do que também transmitiu na sua obra maior, O Nome da Rosa ${ }^{7}$.

A evolução das bibliotecas universitárias ao longo do século XX, sobretudo após a Segunda Guerra Mundial, revela uma tendência cada vez maior para um reforço da componente tecnicista e um maior enfoque na questão do acesso, superando-se, em grande medida, a visão mais tradicional e conservadora. O reconhecimento da importância da informação para o progresso científico, aliado à introdução, intensificada ao longo dos anos, das Tecnologias da Informação e Comunicação nos meios bibliotecários para promoção de um acesso mais ágil e descentralizado, foram condições inestimáveis para provocar a irreversível mudança de paradigma que também se traduziu numa alteração substancial do papel das bibliotecas universitárias.

\section{Os desafios da era digital: que nova mediação está a (tem de) surgir?}

O conceito de 'mediação' é crucial, sobretudo quando nos propomos analisar as condições, as perspetivas, os estudos e os modelos de acesso e de uso da informação, ou seja, como os serviços interagem com os utilizadores e como estes se comportam, de acordo com suas necessidades, situações e contextos, face à informação disponível ${ }^{8}$.

\footnotetext{
${ }^{6}$ ECO, Umberto - A Biblioteca. 4. ${ }^{a}$ ed. Lisboa: Difel, 1998. ISBN 972-29-0174-5.

7 ECO, Umberto - O Nome da rosa. 2. ${ }^{\text {a }}$ ed. Lisboa: Difel, [1980?]. Para um maior detalhe sobre as posições de Umberto Eco, ver: SILVA, Armando Malheiro da; RIBEIRO, Fernanda - Recursos de informação: serviços e utilizadores. Lisboa: Universidade Aberta, 2010. ISBN 978-972-674-672-0.

8 Sobre o conceito de mediação, ver: SILVA, Armando Malheiro da - Mediações e mediadores em Ciência da Informação. Prisma.com: revista de ciências e tecnologias de informação e comunicação do CETAC.MEDIA [Em linha]. 9 (2009). Disponível na WWW em: <URL:http://revistas.ua.pt/index.php/prismacom/article/view/700>.
} 
Segundo Bernard Lamizet e Ahmed Silem, coordenadores do Dictionnaire encyclopédique des sciences de l'information et de la communication, 'mediação' é definida como uma instância articuladora, na comunicação e na vida social, entre a dimensão individual do sujeito e a sua singularidade e a dimensão coletiva da sociabilidade e da relação social ${ }^{9}$. Os autores identificam três tipos de mediação: a codificação linguística e simbólica (um primeiro tipo de mediação), os media e outras formas sociais de comunicação ou interação (um segundo tipo de mediação através da comunicação no espaço social) e um terceiro e último tipo de mediação, que pode formular-se no plural, e que tem a ver com as mediações institucionais e as estratégias de comunicação. Estas são formas de mediação e de comunicação ativadas por sujeitos na sua dimensão institucional de atores sociais, determinadas por lógicas institucionais e orgânicas.

Nos tipos de mediação referidos por Lamizet e Silem cabe, naturalmente, aquela que é praticada pelos serviços de documentação/informação, de que os Arquivos Históricos e as Bibliotecas Públicas e Universitárias são exemplos paradigmáticos: a mediação enquanto comunicação no espaço social e as mediações institucionais/estratégias de comunicação.

A postura dos atores, agentes ou funcionários (arquivistas, bibliotecários e documentalistas) modelou a mediação das respetivas estruturas organizacionais no espaço social reproduzindo dentro delas e projetando através delas o paradigma custodial, patrimonialista e historicista, que se desenvolveu e consolidou no pós-Revolução Francesa. No caso português, a perspetiva que orientou as políticas e as práticas de trabalho nos serviços de informação, particularmente nos públicos, seguiu de perto o modelo francês e europeu, sendo privilegiada a questão da custódia e conservação dos documentos, em detrimento de políticas de acesso amplo e direcionado para as necessidades dos utilizadores ${ }^{10}$.

9 Médiation. In LAMIZET, Bernard; SILEM, Ahmed, dir. - Dictionnaire encyclopédique des sciences de l'information et de la communication. Paris: Ellipses-Édition Marketing, 1997. ISBN 2-7298-4766-9. p. 364-365.

10 Sobre as políticas de informação em Portugal e o desenvolvimento e consolidação do paradigma custodial, patrimonialista e tecnicista, ver: RIBEIRO, Fernanda - Para o estudo do paradigma patrimonialista e custodial: a Inspecção das Bibliotecas e Arquivos e o contributo 
Iniciando-se com Paul Otlet e Henri La Fontaine, por alturas da viragem do século, e afirmando-se ao longo da centúria de novecentos, ganha expressão uma atitude em favor do reforço da vertente técnica da Biblioteconomia, a qual modelou o perfil das bibliotecas e dos serviços de informação, sobretudo na área científico-técnica e nos contextos organizacionais/institucionais (universidades, centros de investigação, serviços de documentação em empresas, etc.). Associada a essa nova atitude vemos surgir uma mediação menos passiva e mais direcionada para o acesso à informação, numa clara preocupação com os interesses dos utilizadores. Esta atitude reforça-se no período posterior à Segunda Guerra Mundial, grandemente motivada pelo desenvolvimento tecnológico e a automatização de componentes diversas dos serviços de informação.

No contexto da informação científico-técnica, percebe-se claramente esta nova tendência e, a partir dos anos setenta, é evidente a transição paradigmática em que a visão tradicional entra em crise e emerge uma nova perspetiva, centrada no acesso e uso da informação. A importância do utilizador passa a ser uma questão essencial para os serviços de informação, que deixam de funcionar numa lógica (passiva) de fornecimento de produtos padronizados (disponibilização dos tradicionais instrumentos de acesso - catálogos, inventários, índices, bibliografias...) para passarem a orientar-se segundo uma ideia de serviço ativo (ou mesmo pró-ativo) que atende às necessidades do utilizador e procura ir ao encontro dos seus perfis específicos e diversificados.

No caso português, sobretudo depois do 25 de abril de 74 em que o país se abre ao exterior e se tornam mais fáceis os contactos com outras realidades, muito mais avançadas em termos de serviços de informação com recurso às tecnologias, as preocupações com um novo tipo de mediação também se começam a fazer sentir. Uma fonte inestimável para avaliar esta mudança de atitude são as atas dos Encontros de Bibliotecários e Arquivistas (organizados pela associação profissional de BAD), onde o teor de variadas comunicações dá conta das preocupações que alguns

de António Ferrão: 1887-1965. Porto: CETAC - Centro de Estudos das Tecnologias e Ciências da Comunicação; Edições Afrontamento, 2008. ISBN 972-36-0948-6. 
dos profissionais mais esclarecidos e melhor posicionados evidenciam, do ponto de vista da gestão dos serviços e da satisfação dos utilizadores.

Uma análise das comunicações publicadas nas atas dos Encontros de $\mathrm{BAD}$, realizados na década de 70 , permite-nos avaliar bem a perspetiva enunciada. A partir da informação disponível é possível não só verificar a importância que era dada à satisfação dos interesses dos utilizadores (de notar que, no Encontro de 1973, houve uma secção intitulada "Utilizadores" e no Encontro de 1978, duas secções também especificamente dedicadas ao tema), mas também identificar um número significativo de comunicações centradas na gestão e na organização das bibliotecas universitárias (ou especializadas) e/ou centros de documentação, muitas delas focadas nos problemas da mediação, com particular ênfase na automatização dos serviços prestados ao público e na organização dos instrumentos de acesso à informação (normalização, disponibilização, etc.). Além disso, a década de 70 foi também a época em que as preocupações com as redes nacionais de Informação, estimuladas pela UNESCO, estiveram no centro das discussões ${ }^{11}$.

Selecionando as comunicações dedicadas especificamente aos utilizadores e às bibliotecas universitárias, sistematizámos a informação disponível nas atas dos quatro encontros realizados entre 1973 e 1979 de forma a que melhor se perceba como tais temas estavam na "ordem do dia" por essa época. Vejamos a síntese dessa informação no quadro seguinte:

\begin{tabular}{|l|r|}
\hline \multicolumn{2}{|c|}{ IV Encontro de BAD - Coimbra, 6 e 7 de dezembro de 1973} \\
\hline N. ${ }^{\circ}$ total de comunicações & 31 \\
\hline $\begin{array}{l}\text { Comunicações sobre utilizadores (uma secção totalmente dedicada ao tema, intitu- } \\
\text { lada "Utilizadores") }\end{array}$ & 14 \\
\hline Comunicações sobre gestão de bibliotecas universitárias/centros de documentação & 4 \\
\hline \multicolumn{2}{|c|}{ V Encontro de BAD - Braga, 6 a 9 de outubro de 1976} \\
\hline N. ${ }^{o}$ total de comunicações & 25 \\
\hline
\end{tabular}

11 O Programa Geral de Informação (PGI) da UNESCO e a implantação do NATIS português (o Sistema Nacional de Informação) foram temas centrais nos encontros de BAD, particularmente nos de 1978 e 1979. 


\begin{tabular}{|l|c|}
\hline $\begin{array}{l}\text { Comunicações sobre bibliotecas universitárias (uma secção intitulada "A Biblioteca } \\
\text { e a Universidade") }\end{array}$ & 5 \\
\hline Comunicações sobre utilizadores & 1 \\
\hline \multicolumn{1}{|c|}{ VI Encontro de BAD - Aveiro, 15 a 17 de março de 1978 } & 29 \\
\hline N. ${ }^{0}$ total de comunicações & 6 \\
\hline $\begin{array}{l}\text { Comunicações sobre utilizadores (1. a secção intitulada "Avaliação das necessidades } \\
\text { dos utilizadores"; } 2 .^{a} \text { secção intitulada "Preparação do utilizador") }\end{array}$ & 6 \\
\hline Comunicações sobre gestão de bibliotecas universitárias/centros de documentação & 65 \\
\hline \multicolumn{1}{|c|}{ VII Encontro de BAD - Lisboa, 14 a 17 de novembro de 1979 } \\
\hline N. ${ }^{o}$ total de comunicações \\
\hline $\begin{array}{l}\text { Comunicações sobre bibliotecas universitárias e serviços de informação (uma secção } \\
\text { intitulada "Planeamento das redes de serviços de documentação e informação") }\end{array}$ & 17 \\
\hline Comunicações sobre utilizadores & 2 \\
\hline
\end{tabular}

Nas últimas duas décadas, uma nova orientação se torna percetível, em matéria de mediação. Com efeito, ocorre uma mudança no sentido de uma perspetiva mais voltada para o conhecimento do utilizador individual (e já não dos perfis de grupos), independentemente do sistema ou serviço que ele utiliza para recuperar informação. Passa-se, portanto de um modelo de análise centrado no sistema (system-oriented) para um outro, centrado no utilizador (user-oriented). A esta nova atitude, somam-se os efeitos da rede global, que atingem todos os setores.

A investigação produzida nos últimos quinze anos, além de evidenciar um aprofundamento teórico muito salutar, debate alguns problemas emergentes, como seja o novo ambiente proporcionado pela Web, meio privilegiado para obter e divulgar informação. Surge, pois, a necessidade de enfrentar desafios antes inexistentes, ou seja, torna-se essencial proceder à adaptação dos modelos desenvolvidos anteriormente ao novo cenário da realidade virtual e colaborativa. É, pois, pertinente perguntar: e neste novo cenário, que mediação está a (tem de) surgir?

A rede "internética" e a tecnologia digital na base da produção, do armazenamento, da recuperação e da disseminação de doses incomensuráveis de informação está a revolucionar e a instaurar o reordenamento possível para os serviços de informação e para os comportamentos dos mediadores (arquivistas, bibliotecários, documentalistas, gestores de 
informação, designers de conteúdos multimédia, etc.) e dos utilizadores (em especial, os info-incluídos e os born digital ou nativos da Internet).

Os serviços de informação têm vindo a multiplicar-se e a diversificar-se ao ponto de também eles se instalarem no ciberespaço. Isto não significa que a função mediadora de comunicação no espaço social e a função mediadora institucional, com as estratégias comunicacionais específicas dos respetivos atores e agentes, tenha desaparecido, mas a verdade é que está a transformar-se e tem de coexistir com um novo tipo de mediação emergente, que é também uma das consequências do paradigma informacional, científico e pós-custodial da Ciência da Informação (CI) que se vem consolidando desde meados do século passado ${ }^{12}$.

No quadro deste novo paradigma emergente e perante as lógicas de mediação que estão a surgir, é pertinente perguntar:

- qual o papel dos mediadores, que atuam nas bibliotecas universitárias e participam na construção da sociedade em rede?

- será que continuam confinados ao domínio de umas quantas especificidades técnicas e normativas, aplicadas à organização e representação da informação, com a finalidade de proporcionar o acesso? - onde cabe o seu anterior papel de guardiães da memória informacional, como fator de identidade?

- onde reside a sua função mediadora e a que âmbito se circunscreve?

A consolidação da CI como área científica com fundamentos teórico-metodológicos sólidos e consistentes é, a nosso ver, garantia de que os graduados neste campo do saber estarão preparados para enfrentar os novos desafios da sociedade em rede e estarão à altura de estudar e compreender o fenómeno info-comunicacional em toda a sua complexidade.

12 Sobre o paradigma informacional, científico e pós-custodial, ver: SILVA, Armando Malheiro da; RIBEIRO, Fernanda - Documentation/Information and their paradigms: characterization and importance in research, education, and professional practice. Knowledge Organization: international journal devoted to concept, theory, classification, indexing and knowledge representation. Würtzburg. ISSN 0943-7444. 39:2 (2012) 111-124. 
Continuarão a assumir-se como mediadores de informação, mas com perfil de experts habilitados a avaliar, seleccionar e fornecer apenas informação útil e pertinente ao utilizador que a procura.

E continuarão, certamente, a afirmar-se como garantes da preservação da memória, aspeto que, dada a volatilidade a que está sujeita a informação digital, será, sem dúvida, considerado uma função muito especializada e muito reconhecida socialmente, requerendo uma preparação adequada que não dispensará uma base científica bem consolidada.

\section{Referências bibliográficas}

ECO, Umberto - A Biblioteca. 4. ${ }^{\mathrm{a}}$ ed. Lisboa: Difel, 1998. ISBN 972-29-0174-5.

ECO, Umberto - O Nome da rosa. $2 .^{\text {a }}$ ed. Lisboa: Difel, [1980?].

ENCONTRO DOS BIBLIOTECÁRIOS, ARQUIVISTAS E DOCUMENTALISTAS PORTUGUESES, 4. ${ }^{\circ}$, Coimbra, 1973 - Actas. Coimbra: Faculdade de Letras, Universidade de Coimbra, 1974.

ENCONTRO DOS BIBLIOTECÁRIOS, ARQuivistAs E DOCUMENTALISTAS PORTUGUESES, 5. ${ }^{\circ}$, Braga, 1976 - Actas. Braga: V E.B.A.P., 1976.

ENCONTRO DOS BIBLIOTECÁRIOS, ARQUIVISTAS E DOCUMENTALISTAS PORTUGUESES, 6. ${ }^{\circ}$, Aveiro, 1978 - Actas. Aveiro: VI E.B.A.P., 1978.

ENCONTRO DOS BIBLIOTECÁRIOS, ARQUIVISTAS E DOCUMENTALISTAS PORTUGUESES, 7. ${ }^{\circ}$, Lisboa, 1979 - Actas. Lisboa: VII E.B.A.P., 1979. 2 vol.

FERRÃO, António - "Gabriel Pereira: a sua educação e cultura, a sua época e a sua obra”. Anais das Bibliotecas e Arquivos. Lisboa. 2. ${ }^{a}$ série. 19 (1947) p. 61-84. HARRIS, Michael H. - History of libraries in the Western world. 4th ed. Lanham; London: The Scarecrow Press, 1995. ISBN 0-8108-2972-X.

LAMIZET, Bernard; SILEM, Ahmed, dir. - Dictionnaire encyclopédique des sciences de l'information et de la communication. Paris: Ellipses-Édition Marketing, 1997. ISBN 2-7298-4766-9.

LERNER, Fred - The Story of libraries from the invention of writing to the computer age. New York: Continuum, 1998. ISBN 0-8264-1114-2.

MASSON, André; SALVAN, Paule - Les Bibliothèques. 4.ème éd. mise à jour. Paris: PUF, 1975. 
RIBEIRO, Fernanda - Para o estudo do paradigma patrimonialista e custodial: a Inspecção das Bibliotecas e Arquivos e o contributo de António Ferrão: 1887-1965. Porto: CETAC - Centro de Estudos das Tecnologias e Ciências da Comunicação; Edições Afrontamento, 2008. ISBN 972-36-0948-6.

SILVA, Armando Malheiro da - "Mediações e mediadores em Ciência da Informação". Prisma.com: revista de ciências e tecnologias de informação e comunicação do CETAC.MEDIA [Em linha]. 9 (2009). Disponível na WWW em: <URL:http:// revistas.ua.pt/index.php/prismacom/article/view/700>.

SILVA, Armando Malheiro da; RIBEIRO, Fernanda - "Documentation/Information and their paradigms: characterization and importance in research, education, and professional practice”. Knowledge Organization: international journal devoted to concept, theory, classification, indexing and knowledge representation. Würtzburg. ISSN 0943-7444. 39:2 (2012) 111-124.

SILVA, Armando Malheiro da; RIBEIRO, Fernanda - Recursos de informação: serviços e utilizadores. Lisboa: Universidade Aberta, 2010. ISBN 978-972-674-672-0. 
José Augusto Cardoso Bernardes é Professor da Faculdade de Letras da Universidade de Coimbra e Diretor da Biblioteca Geral da Universidade

Ana Maria Eva Miguéis é coordenadora do Serviço Integrado das Bibliotecas da Universidade de Coimbra

Carla Ferreira é bibliotecária nos Serviços de Biblioteca e Documentação da Faculdade de Letras da Universidade de Coimbra. 


\section{Série Documentos}

Imprensa da Universidade de Coimbra

Coimbra University Press

2015

C •

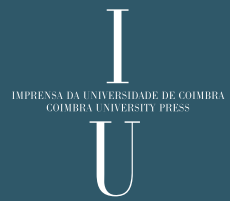

